\title{
New Functional Polymers for Medical Applications
}

\author{
P. FERruti* and E. RaNUCCI \\ Dipartimento di Ingegneria Meccanica, Università di Brescia, \\ via D. Valotti 925060 Brescia Italy
}

(Received November 26, 1990)

\begin{abstract}
Recent results on both cationic and anionic functional polymers and macromonomers obtained by Michael-type polyaddition reactions as well as a new method for obtaining sec-aminoend-functionalized PEG, are described. The new families of macromolecular substances include poly(ethyleneglycol-amido-amine-urethanes) (PEGAAU), block copolymers between poly(ethyleneglycols) and poly(amido-amines) (PEG-PAA), block copolymers between poly(ethyleneglycols) and poly(amido-thioether-amines) (PEG-PATA), and poly(thioether-amido-acids) (PTAA). Crosslinked, potentially hydrolyzable carboxylated resins based on the last family are also reported. The new polymers and macromonomers are mainly intended for surface-modification of common materials and biomaterials through surface-grafting.

KEY WORDS Ionic Macromonomers/Amino Polymers/Carboxylated Polymers/ Poly(amido-amines)/ Poly(ethyleneglycol) Aminated Derivatives/ Poly(ethyleneglycol)-polymeric Amines Block Copolymers/ Degradable Polymeric Acids/ Degradable Cationic Resins.
\end{abstract}

Surface grafting of ionic groups on polymeric materials is an important way for modifying their biological performances. In principle, this is best achieved by using suitably end-functionalized ionic macromonomers, since many ionic functions are introduced with a single reaction step; furthermore, if the chains are grafted only at their ends, these functions are more easily available for reactions occurring in aqueous phase.

Unique opportunities for obtaining ionic macromonomers are offered by the following Michael-type polyaddition reactions:<smiles>[Y]C=CC(=O)N([R])C(=O)C=C[Y1]([Y])=[X]</smiles>

$$
\mathrm{X}=\underset{\mathrm{R}^{3}}{\mathrm{~N}} ; \begin{array}{lll}
\mathrm{N}-\mathrm{R}^{5}-\mathrm{N} & \mathrm{I} \\
\mathrm{R}^{4} & \mathrm{R}^{4}
\end{array}
$$

These reactions, in fact, have in common some peculiar features. Many of them take place readily in water or alcohols, at room temperature, and, in case of amines $^{(1-3)}$ and aminated bis-thiols ${ }^{(3-4)}$ without added catalysts. Almost all 
aliphatic amines, bis-thiols, and bis-acrylamides, can be used as monomers. Several other functions, including ter-amino groups and carboxy groups, if present in the monomers do not interfere with the polymerization process. Besides, the polymers obtained with amines, i.e. poly(amidoamines) (PAA's) are basic per se, and have been thorougly studied on this respect ${ }^{9-17)}$

Moreover, by performing the polyaddition reactions with an excess of one of the two comonomers, macromonomeric products prevailingly end-functionalized with the excess function are easily obtained. For example, both acrylamidoand sec-amino-terminated PAA's have been prepared, and further reacted either with surfaces bearing complementary functions, resulting in surface-grafting ${ }^{(18-20)}$ or with other macromonomers also bearing complementary functions, thus obtaining block and graft copolymers $(21-25)$. Many of these products, as well as PAA-based crosslinked resins, 26-28) are able to stably adsorb heparin from plasma or blood.

The aim of this paper is to relate some of our most recent results on functional polymers and macromonomers. Four new families of polymeric substances have been obtained, namely poly(ethyleneglycol-amido-amine-urethanes) (PEGAAU), block copolymers between poly(ethyleneglycols) and poly(amido-amines) (PEG-PAA), block copolymers between poly(ethyleneglycols) and poly(amido-thioether-amines) (PEG-PATA), and poly(thioether-amido-acids) (PTAA). The starting point for the preparation of the first three families of polymers is a new method for preparing sec-amino-terminated-poly(ethyleneglycols) (PEGAM's) from any commercial sample of poly(ethyleneglycol) (PEG). All these new polymers will be dealt with separately, starting from the latter

\section{PEGAM's}

Several methods have been proposed in the literature for obtaining PEG's terminated with amino groups ${ }^{(29-3)}$, and some of these are presently being commercialized. However, it is not easy to find in commerce, or in the literature, samples of amino-terminated PEG's with the characteristics which are required for properly performing a stepwise polyaddition reaction. On the contrary, well characterized samples of PEG with narrow molecular weight distributions are available within an ample range of molecular weights. The new functionalization method studied by our group allows to transform all available PEG samples into piperazinyl-terminated PEG's, which are expected to be particularly suitable for further polyaddition reactions by analogy with our previous findings with piperazine ${ }^{32}$. The reaction pathway is the following:<smiles>OCCCO</smiles><smiles>O=C1C2CNC1C2</smiles><smiles>CC(C)(C)[Mg]Cl</smiles>

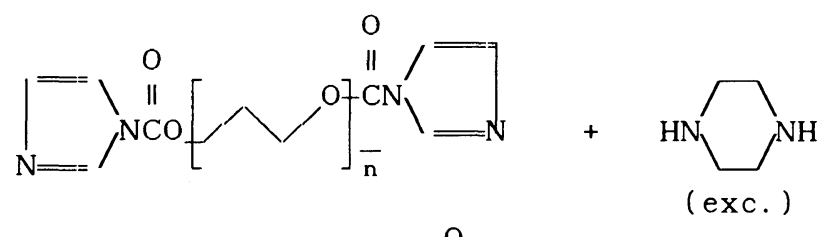
$\underset{-2 \mathrm{HN}_{1}^{\prime}}{\stackrel{\mathrm{CHCl}_{3}, \quad \text { room temperature }}{=}}$<smiles>CCCCOC(=O)N1CCNCC1[N+](=O)OCCCC(C)(C)N1CCNCC1</smiles>

$$
\bar{n}=10 \text { to } 200
$$


The first step involves the reaction of PEG's with excess $\mathrm{N}, \mathrm{N}^{\prime}$-carbonyldiimidazole (CDI) in alcohol-free chloroform and at room temperature to give quantitatively after a few minutes PEG imidazolylformates These are not rapidly decomposed by water at room temperature, and are not extracted by water from their chloroform solutions. On the contrary, CDI is rapidly decomposed by water, and the imidazole formed is completely extractable by water from chloroform. Consequently, enough CDI to overcome any moisture present in the reaction mixture can be added without harm. This allows to avoid previous drying of commercial PEG's, which is not a very simple procedure ${ }^{(33)}$. A large excess of piperazine ( $\left.20 \mathrm{~mol} / \mathrm{mol} \mathrm{PEG}\right)$ is used in the second step. The excess piperazine is eliminated by multiple extractions with $10 \%$ potassium nitrate solution, and finally with water. The purity of the products was checked by ${ }^{1} \mathrm{H}$ NMR, elemental analysis, titration against standard acid, and GPC. The same functionalization reaction can be performed with bis(sec.amines) other than piperazine, as well as with bis(primary amines).

PEGAUU

Direct polyaddition of PEGAM's to bis-acrylamides results in the title polymers:<smiles>[Y]C=CC(=O)N([R])C(=O)C=C</smiles>

PEGAAU

$$
\overline{\mathrm{n}}=10 \text { to } 200
$$

The polymerization reaction takes place easily in water at room temperature, and the products can be isolated by evaporating the reaction mixtures to dryness in vacuo.

It may be observed that the repeating unit of PEGAAU's may weigh up to about 10000 , corresponding to a weight percentage of PEG higher than $95 \%$. Therefore, even if strictly speaking the above polymers are poly(PEG-amido-amine-urethanes), broadly speaking many of them may be considered as high molecular weight PEG's containing a few aminic and a few potentially hydrolyzable amidic and urethane groups along their main chain.

Some PEGAAU's are reported in Table I

\section{PEG-PAA}

The introduction of PEGAM's as comonomers in the preparation of PAA's leads to polymeric products which are essentially PEG-PAA block copolymers.

For example, by choosing piperazine $(P)$ an 1,4-bisacryloylpiperazine (BAP) as model diaminic comonomer and bisacrylamide, respectively, the copolymers reported in Table II were obtained. The reaction: 
Table I. Some poly(amido-amine-urethanes) (PEGAAUS's).<smiles>[Y]CC(C)N=CCNC(=O)COC(C)COC(=O)N=C=CNCCC(=O)N([R])[R]</smiles>

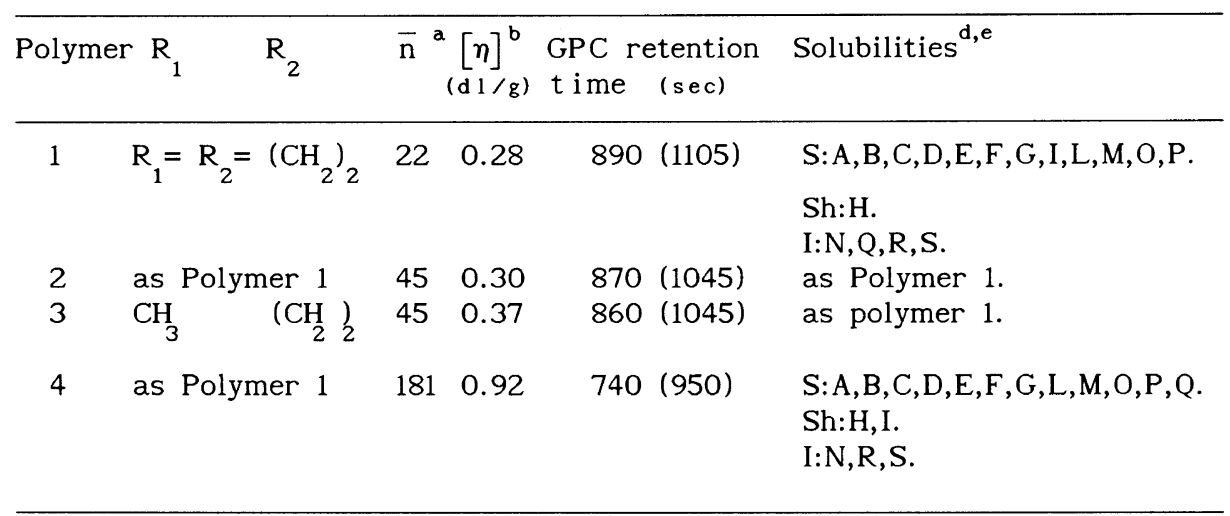

a Number-average polymerization degree of the starting PEG.

b At $30^{\circ}$ in $0.1 \mathrm{M}$ phosphate buffer $\mathrm{pH}$ 8.0.

The retention times of the starting PEG's are given in parentheses.

${ }^{d} \mathrm{~S}=$ soluble; $\mathrm{Sh}=$ soluble near the boiling point; $\mathrm{I}=$ insoluble. Solvents tried: A:water; B:phosphate buffer $\mathrm{pH}$ 8.0; C:acetate buffer $\mathrm{pH}$ 4.5; D:formamide; E:dimethylformamide; F:dimethylsulphoxide; G:methanol; H: isopropanol; I: ethylacetate; L:acetone; M:acetonitrile; N:ether; O:dioxane;P:chloroform; Q: toluene; R:cyclohexane; S:n-heptane.

e All starting PEG's have the following solubilities: S: A, B, C,D,E,F, G, $\mathrm{H}$ (Sh for PEG 8000), I,L,M,O,P,Q; I: N,R,S.

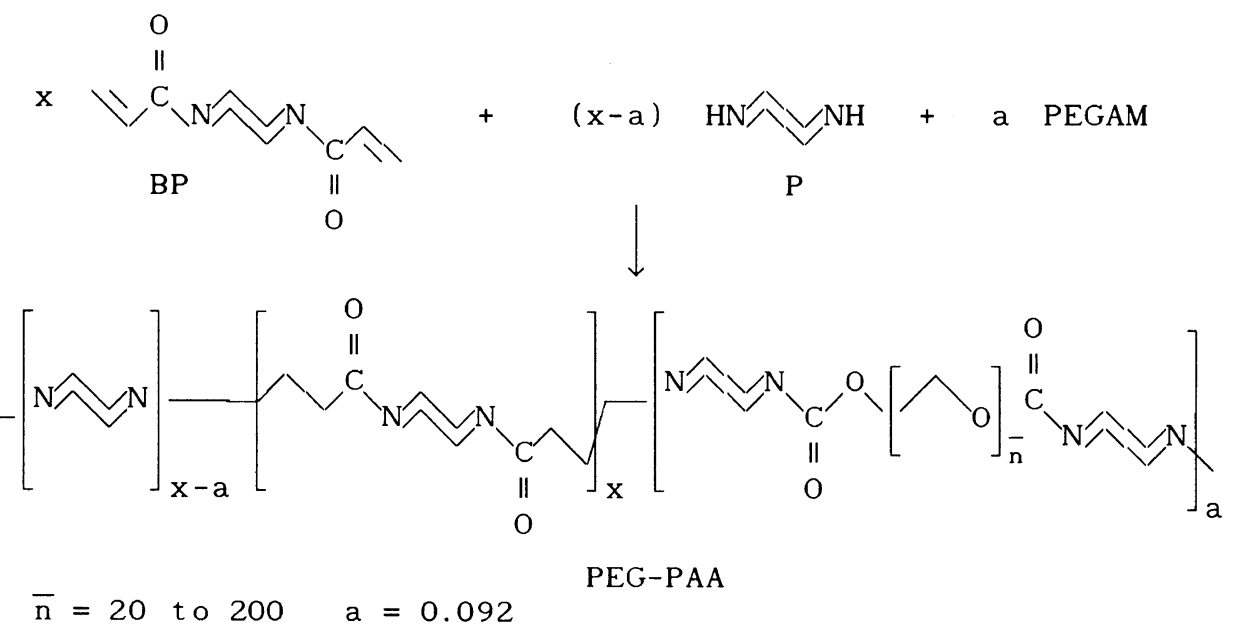

was performed in water at room temperature, as usual for PAA's, and lasted about three days.

It may be observed that the molar fraction of piperazine in the 
polymerizing mixture was the same in all cases. Consequently, the copolymers were different in the relative length of their PEG and PAA segments, as well as in their PEG content by weight. For comparison purposes, we have also prepared a PAA homopolymer with the same recipe, but omitting the addition of PEGAM's. This homopolymer can be reasonably considered as representative of the PAA blocks within PEG-PAA's. It is also reported in Table II.

It may be added that by using an excess bis-acrylamide in the monomer mixtures, both PEGAAU's and PEGPAA's macromonomers end-capped with acrylamido groups have been prepared. Grafting experiments on various materials are presently being performed.

\section{PEG-PATA}

Poly(amido-thioether-amines) (PATA) are a new family of polymeric amines structurally related to PAA's. They are obtained by stepwise polyaddition of bis( $\beta$-mercaptoethylamines) to bisacrylamides in aqueous solution at slightly acidic $\mathrm{pH}^{(7)}$. Under these conditions, primary and secondary amines do not add to bisacrylamides (1) Consequently, it was not possible to prepare PEG-PATA copolymers in a single step, as in the case of PEG-PAA's.

The preparation was performed in two steps. In the first step, new PEGAM-based macromonomers (PEGAMBAC) were prepared by reaction of PEGAM's with excess bis-acrylamides. In the second step, reaction mixtures containing PEGAMBAC's, N,N'-bis( $\beta$-mercaptoethylamines), and bis-acrylamides, were treated with water and enough acetic acid to obtain a clear solution with a $\mathrm{pH}$ of

Table II. Some poly(ethyleneglycol) - poly(amidoamine) block copolymers (PEG-PAA's), and model PAA.

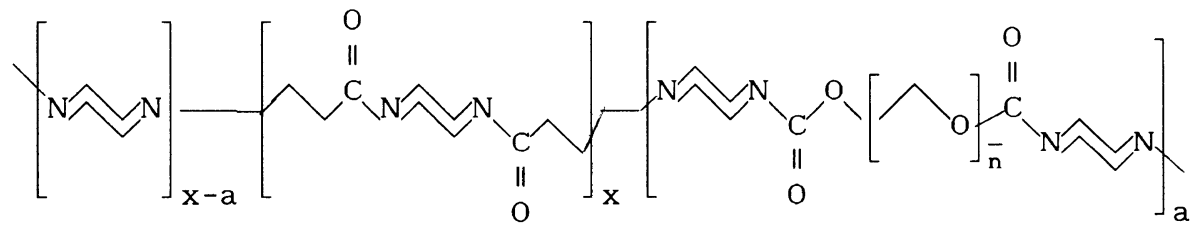

\begin{tabular}{|c|c|c|c|c|c|}
\hline$N$ & $\bar{n}^{a}$ & $\begin{array}{l}\text { We ight } \% \\
\text { PEG }\end{array}$ & ${ }_{(d 1 / g)}^{[\eta]^{d}}$ & $\begin{array}{l}\text { GPC retention } \\
\text { times }\left(\mathrm{sec}^{\mathrm{e}}\right.\end{array}$ & Solubilities ${ }^{f, g}$ \\
\hline 1 & 22 & 57.26 & 0.29 & 890 & $\begin{array}{l}\text { S:A,B,C,P. } \\
\text { Sh:D. } \\
\text { I:E,F, G,H,I,L,M,N,O,Q,R,S. }\end{array}$ \\
\hline 2 & 45 & 71.04 & 0.31 & 870 & as Polymer 1. \\
\hline 3 & 181 & 85.15 & 0.39 & 870 & $\begin{array}{l}\text { S: A, B, C,D E, F, M,P. } \\
\text { Sh: G. } \\
I: H, I, L, N, O, Q, R, S .\end{array}$ \\
\hline 4 & $-^{b}$ & - & 0.08 & 1080 & $\begin{array}{l}\text { S:A,B,C,D,E,F,P. } \\
\text { I: G,H,I,L,M,N,O,Q,R,S. }\end{array}$ \\
\hline
\end{tabular}

a See the corresponding footnote to Table 1.

bodel PAA.

$\mathrm{a} /(\mathrm{x}-\mathrm{a})=0.092$ in all cases.

d See footnotes b to Table 1.

e Retention times of starting PEG's are reported in Table 1.

${ }^{\mathrm{f}, \mathrm{g}}$ See footnotes $\mathrm{d}$ and e to Table 1 .

h High molecular weight PAA samples of the same structure are insoluble in chlorof orm. 
about 5.5. After carefully purging with nitrogen, the reaction mixtures were allowed to stand at room temperature for several days.

The whole process could be also performed by a one-pot procedure, treating PEGAM's in water solution with excess bis-acrylamide, allowing to react completely, then adding acetic acid and enough $N, N^{\prime}$-bis-( $\beta$-mercaptoethyl)amine to achieve the desired stoicheiometry. If the bis-acrylamide in the final mixture is in excess, on a molar basis, with respect to the sum of PEGAM and $\mathrm{N}, \mathrm{N}^{\prime}$-bis( $\beta$-mercaptoethylamine), a vinyl-terminated PEG-PATA macromonomer was obtained.

By choosing BP and 2,2'-(1,4-piperazinediyl)diethanethiol (PDE) as model monomers, the whole process can be represented as follows

1) a PEGAM + $\mathrm{x}$ BP

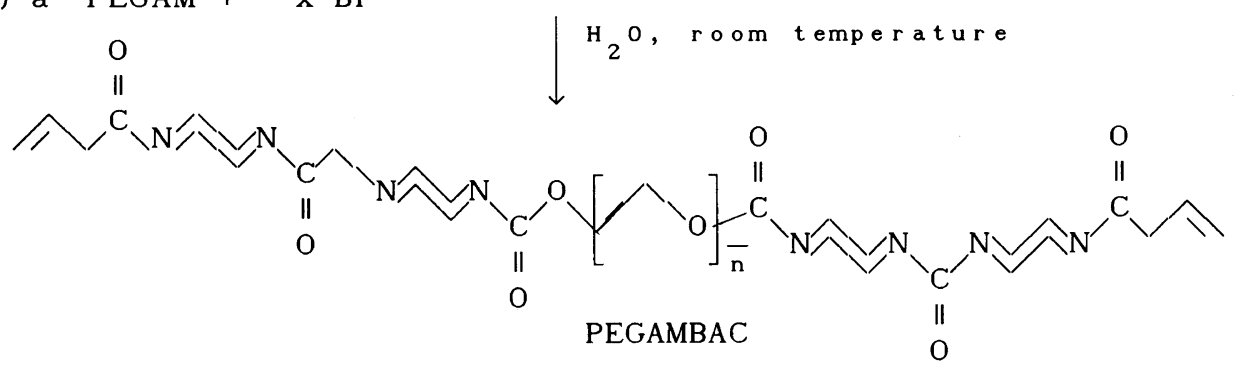

$+(x-2 a) \quad B P$

2) a PEGAMBAC + $+(x-2 a) B P+(x-a)$ HS

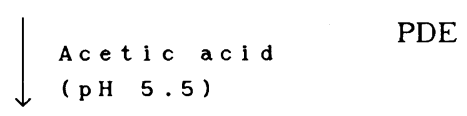

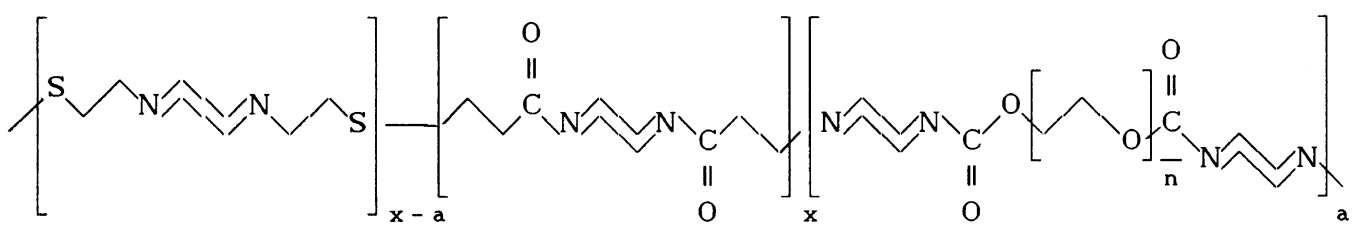

PEG-PATA

$$
\bar{n}=20 \text { to } 200 ; a=0.124
$$

As in the previous case, a model PATA homopolymer was prepared with the same amounts of BP and PDE as in copolymers' preparation. Some PEG-PATA copolymers, as well as model PATA, are reported in Table III. It may be observed that, as in the case of PEG-PAA's, the molar fraction of PEGAM is the same in all samples, which, consequently, differ only by the different relative weights of their PEG and PATA segments, the latter being the same throughout the whole series.

\section{PTAA}

These polymeric acids were prepared by Michael-type polyaddition of bis-thiols to 2,2-bis(acrylamido)acetic acid (BAAC) ${ }^{(35)}$ 
<smiles>[X]C=CC(=O)NC(NC(=O)C=CC(C)C(C)C)S(=O)SCC(=O)NC(NC(=O)CCCC)C(=O)O</smiles>

Table III Some poly(ethyleneglycol) - poly(amido-thioether-amine) block copolymers (PEG-PATA's), and model PATA.

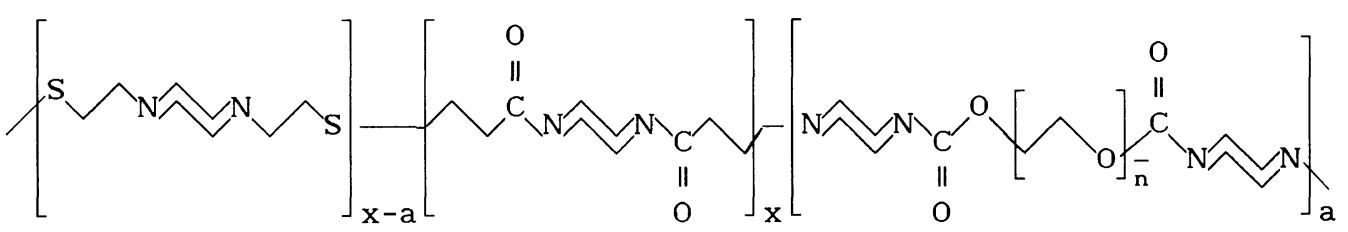

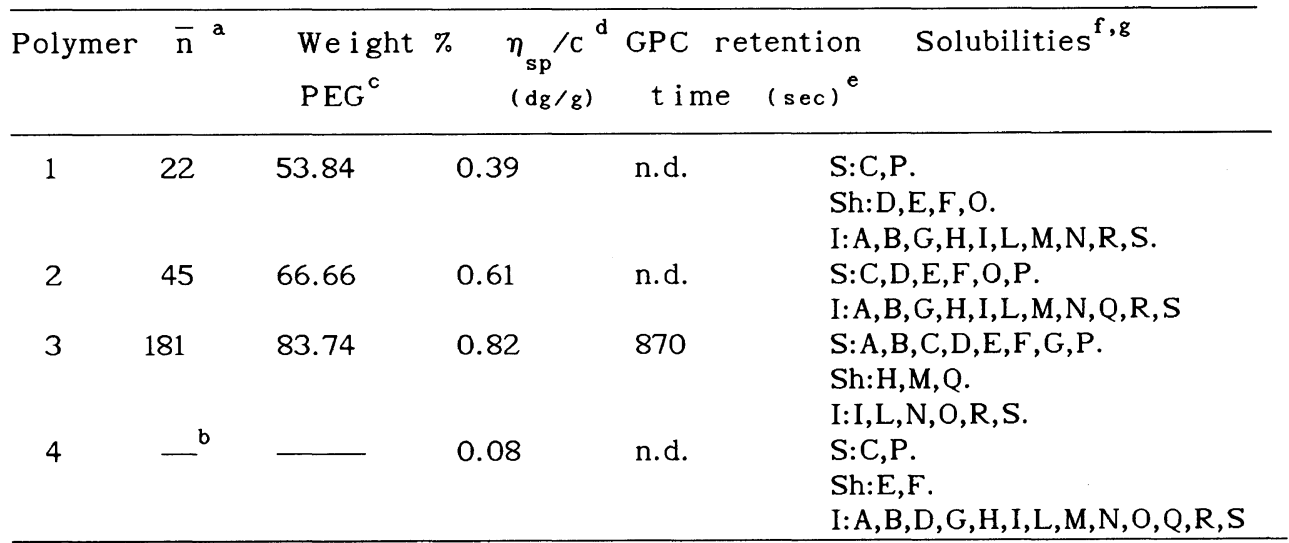

${ }^{a}$ See the corresponding footnote to Table I.

b Model PATA.

$\mathrm{a} /(\mathrm{a}-\mathrm{x})=0.124$ in all cases.

${ }^{\mathrm{d}} \mathrm{C}=0.1 \%$ in $0.1 \mathrm{M}$ acetate buffer $\mathrm{pH} 4.62$.

e Retention times of this starting PEG's are reported in Table I.

${ }^{f, g}$ See footnotes $d$ and e to Table I.

PTAA

These polymeric acids were prepared by Michael-type polyaddition of bis-thiols to 2,2-bis(acrylamido)acetic acid (BAAC) $\stackrel{(35)}{:}$

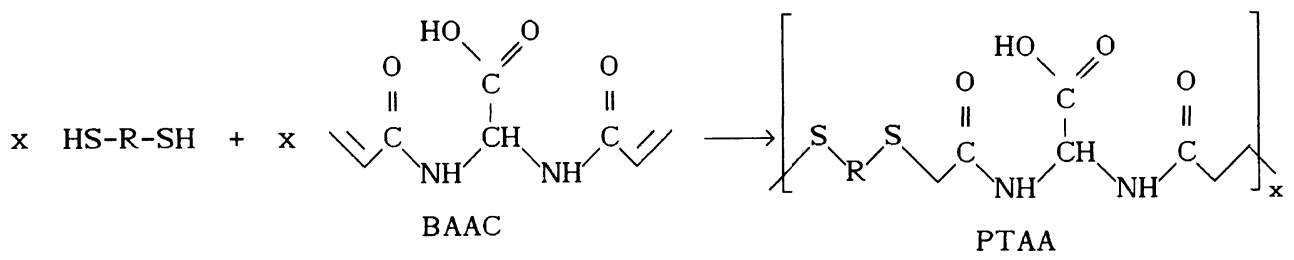

A related polymerization technique was used in the past to synthesize polymeric products containing no additional functions besides the thioether and amidic functions, starting from bis-thiols and unfunctionalized bis-acrylamides ${ }^{(36)}$. However, BAAC has not been considered so far as a monomer for stepwise polyadditions. The polymerization reaction leading to PATA's was performed in lower alcohols or aqueous-alcoholic mixtures, and in the presence 
of 1.2 moles triethylamine per mol acid, the excess base acting as catalyst. Some PTAA's are reported in Table IV.

It may be observed that PTAA's are polymeric acids containing, besides side carboxy groups, chemical bonds in their main chain which are cleavable in

Table IV. Some poly(thioether-amido-acids) (PTAA's)

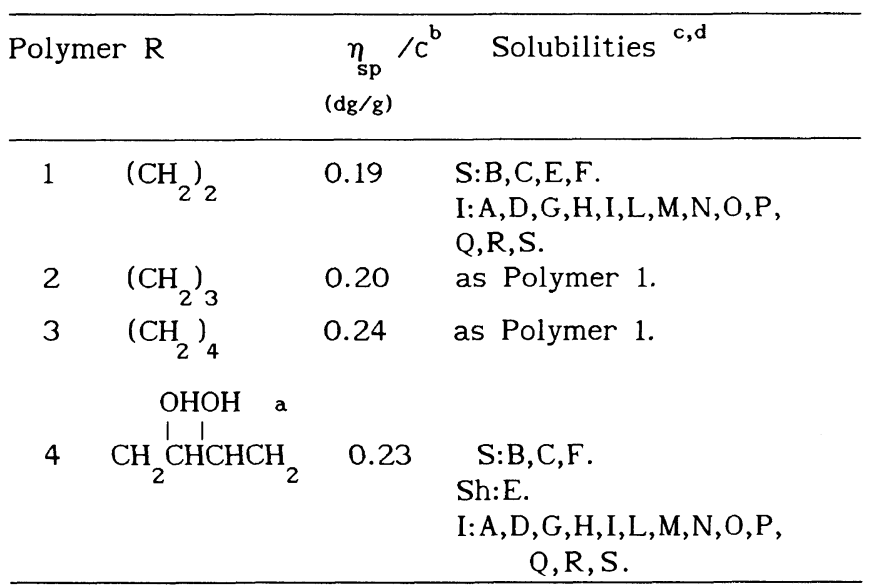

a Threo isomer.

b In dimethylsulphoxide at $30^{\circ}$. The values refer to samples obtained with triethylamine as catalyst. Samples obtained with sodium carbonates have intrinsic viscosities in the range of $0.5 \mathrm{dl} / \mathrm{g}$.

c, d See footnotes d,e to Table I.

The protonation behaviour of PTAA's has been studied by potentiometric titration. Preliminary results ${ }^{(40)}$ have shown that PTAA's have low basicity constants, compatible with those of many fairly simple carboxylic They show the typical polyelectrolyte behaviour and appear to be stronger acids than poly(acrylic) and poly(methacrylic) acid.

Crosslinked PTAA Resins

As expected for a Michael-type polymerization, by performing the polyaddition of a bisthiol to BAAC with an excess of the latter, macromonomers end-capped with acrylamido groups are obtained. These, in turn, can be used for preparing crosslinked resins, by curing with radical initiators with or without the addition of a vinyl monomer. By choosing polymer (1) of Table IV as representative of the whole family, we prepared a sample starting from a monomer mixture with a bis-thiol/BAAC ratio equal to 0.8 . Without isolation, this sample was mixed with three parts by weight $\mathrm{N}$-vinyl-2-pyrrolidinone, and warmed in the presence of a radical initiator. A crosslinked resin $\left(R_{1}\right)$ was obtained. The same treatment performed without the addition of $\mathrm{N}$-vinyl-2-pyrrolidinone also gave a crosslinked resin $\left(R_{2}\right)$. After carefully extracting with media solvent for the linear polymers, the resins were characterized for their ion-exchange capacity, and their water uptake in aqueous media either as free acids, or as sodium salts. We found that $\left(R_{1}\right)$ and $\left(R_{2}\right)$ have an ion exchange capacity of $1.068 \times 10^{-3}$ moles $/ g$ and $3.65 \times 10^{-3}$ moles/g, respectively. The ion exchange capacity of the linear polymer is 3.76 $\times 10^{-3}$ moles/g. 
It may be observed that $\left(R_{1}\right)$ has a ion-exchange capacity higher than expected, probably because either $\mathrm{N}$-vinyl-2-pyrrolidinone did not polymerize completely, or it polymerized, in part, to soluble homopolymer. On the other hand, resin $\left(\mathrm{R}_{2}\right)$ has the expected ion-exchange capacity.

The water uptakes of the two resins are 1.69 and $1.41 \mathrm{~g} / \mathrm{g}$ (free acid) and 11.31 and $9.60 \mathrm{~g} / \mathrm{g}$ (sodium salt) respectively.

It may be noted that the water uptake of both resins increases markedly by passing from the free acids to their dissociated forms.

\section{REFERENCES}

1. F.Danusso and P.Ferruti, Polymer, 11, 88 (1970).

2. P.Ferruti, in "Biomedical Applications of Poly(amidoamines) in "Biomedical and Dental Applications of Polymers" (Eds.G.C. Gebelein and F.K. Koblitz), Plenum Publishing Corp., New York, p. $39-57$ (1981) and references therefrom.

3. P.Ferruti, M.A. Marchisio and R.Barbucci, Polymer 26, 1336 (1985) and references therefrom.

4. P.Ferruti and E.Ranucci, J. Polym. Sci. Polym. Lett., 26, 357 (1988).

5. E.Ranucci and P.Ferruti, Polymer, in press.

6. P.Ferruti, E.Ranucci and L.Depero, Makromol. Chem. Rapid. Commun., 9, 807 (1988).

7. P.Ferruti, E.Ranucci and L.Depero, Polymer, 30, 157 (1989).

8. E.Ranucci and P.Ferruti, Chim. Ind.(Milan), 72, 407 (1990).

9. R.Barbucci, P.Ferruti, C.Improta, M.Delfini, A.L.Segre and F.Conti, Polymer, 19, 1329 (1978).

10. R.Barbucci, P.Ferruti, C.Improta, M.La Torraca, L.Oliva and M.C. Tanzi, Polymer, 20, 1299 (1979).

11. R.Barbucci and P.Ferruti, Polymer, 20, 1061 (1979).

12. R.Barbucci, P.Ferruti, M.Micheloni,M.Delfini, A.L. Segre and F.Conti, Polymer, 21, 81 (1980).

13. R.Barbucci, M.Casolaro, P.Ferruti, V.Barone, F.Lelj and L.Oliva, Macromolecules, 14, 1203 (1981).

14. R.Barbucci, M.Casolaro, N.Danzo, M.C. Beni, V.Barone and P. Ferruti, Gazz. Chim. It., 112, 105 (1982).

15. P.Ferruti, N.Danzo, L.Oliva, R.Barbucci and V.Barone, J. Chem. Soc. Dalton, 1981, 541.

16. R.Barbucci, V.Barone, P.Ferruti and L.Oliva, J. Polym. Sci. Polym. Symp. Edn., 69, 49 (1981).

17. P.Ferruti, L.Oliva, R.Barbucci and M.C. Tanzi, Inorg. Chim. Acta, 41, 25 (1980).

18. P.Ferruti, I.Domini, R.Barbucci, M.C. Beni, E.Dispensa, M.A. Marchisio and M.C. Tanzi, Biomaterials, 4, 218 (1983).

S.Sancasciani,

19. R.Barbucci, M.Benvenuti, G.Casini, P.Ferruti, and M.Nocentini, Makromol. Chem., 186, 2291 (1985).

20. G.Azzuoli, R.Barbucci, M.Benvenuti, P.Ferruti and M.Nocentini, Makromol. Chem., 8, 61 (1987).

21. P.Ferruti, D.Arnoldi, M.A. Marchisio, E.Martuscelli, M.Riva and L.Provenzale, J. Polym. Sci Polym. Chem. Edn., 15, 2151 (1977).

22. P.Ferruti, E.Martuscelli, G.Nicolais and F.Riva, Polymer, 18, 387 (1977).

23. E.Martuscelli, G.Nicolais, F.Riva, P.Ferruti and L. Provenzale, Polymer, 19, 1329 (1978).

24. M.C. Tanzi, R.Fumero, M.Levi and G.Tieghi "New Heparinizable, Blood Compatible Segmented Polyurethanes: Properties and Stability Tests" in "Polyurethanes in Biomediacal Engeneering II". (H.Planck, I.Siré, M.Dauner 
and G.Egbers Eds.) Elsivier, Amsterdam, 1987 p 197-212.

25. R.Barbucci, M.Benvenuti, G.Dal Maso, P.Ferruti, M.Nocentini, R.Russo, F.Tempesti, R.Duncan, J.F.Bridges and L.A.McCormick "A new material for biomedical application" in "Polymers in Medicine III) (C.Migliaresi, G.Nicolais, P.Giusti and E.Chiellini Eds.) Elsevier, Amsterdam, 1987

26. M.A. Marchisio, P.Ferruti, T.Longo and F.Danusso, US Patent, 3,865,723 (1975).

27. M.A. Marchisio, T.Longo and P.Ferruti, Experientia, 29, 93 (1973).

28. M.A. Marchisio, P.Ferruti, S.Bertoli, G. Barbiano di Belgiojoso,

Samour and K.D. Volter, "A Novel Approach to the Problems of Hemodialysis: the Use of a De-heparinizing Filter" in "Polymer in Medicine III" (Eds. C.Migliaresi, L.Nicolais, P.Giusti and E.Chiellini), Elsivier, Amsterdam, 1988 p 111-120.

29. A.F. Buckmann, M.O.Morr and C.Johansson, Makromol. Chem., 182, 1379 (1981).

30. Zalipsky,S., Gilon,C. and Zilkha,A., Eur. Polym. J., 19, 1177 (1983).

31. Okamoto,A., Toyoshima,K. and Mita,I. Eur. Polym. J., 19, 314 (1983).

32. F.Danusso, P.Ferruti and G. Ferroni, Chim. Ind.(Milan), 49, 271 (1967).

33. J.M. Harris, J. Macromol. Sci. Rev.Macromol. Chem. Phys. C25, 1985, 325.

34. E.Ranucci and P.Ferruti, Synthetic Comm., in press, 1990.

35. E.Ranucci and P.Ferruti, presented at the 4th International Conference on Polymers in Medicine, Riva del Garda, Italy, September 11-13, 1990.

36. J.G. Ericksson, J.Polym. Sci. 4, 519 (1966).

37. M.Vert and R.W. Lenz, Polym. Prepr. (Am. Chem. Soc. Div. Polym. Chem., 20, 608 (1979).

38. D.B. Johns, R.W. Lenz and M. Vert, J. Bioact. Compatible Polym., 1, 7(1986).

39. P.Ferruti and E.Ranucci, in "High Performance Biomaterials: a Comprehensive Guide to Medical and Pharmaceutical Applications", Michael Szycher Ed., Technomic Co., in press.

40. M.Casolaro, R.Barbucci, P.Ferruti and E.Ranucci, presented at the "Congresso Interdivisionale della Chimica Italiana, San Benedetto del Tronto , $30^{\text {th }}$ Sept. $-5^{\text {th }}$ Oct. 1990. 